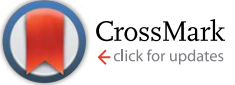

Cite this: RSC Adv., 2017, 7, 11572

Received 29th December 2016 Accepted 30th January 2017

DOI: 10.1039/c6ra28821a

rsc.li/rsc-advances

\title{
Flexible and low-voltage organic phototransistors
}

\author{
Fanfan $\mathrm{Yu}^{\text {a }}$ Shaohua Wu, ${ }^{a}$ Xiaohong Wang, ${ }^{\text {ab }}$ Guobing Zhang, ${ }^{a}$ Hongbo Lu ${ }^{\text {ab }}$ \\ and Longzhen Qiu*ab
}

A stripping procedure was demonstrated for the preparation of an ultra-smooth aluminum electrode. After potentiostatic anodization and treatment with a self-assembled monolayer (SAM) of $n$-octadecyl phosphonic acid, $\mathrm{AlO}_{x}-\mathrm{SAM}$ hybrid dielectrics were grown onto flexible, stripped aluminum combining low cost manufacture under ambient conditions with excellent dielectric characteristics (negligible leakage, $114.3 \mathrm{nF} \mathrm{cm}{ }^{-2}$ capacitance). Field effect transistors using dinaphtho[2,3-b:2', 3'-f]thieno[3,2-b] thiophene (DNTT) as an organic semiconductor can be operated below $-5 \mathrm{~V}$ with a high mobility of 0.53 $\mathrm{cm}^{2} \mathrm{~V}^{-1} \mathrm{~s}^{-1}$, high on/off current ratio of $1.7 \times 10^{5}$, low subthreshold slope of $210 \mathrm{mV} \mathrm{dec}{ }^{-1}$, and good threshold of $-1.51 \mathrm{~V}$. Moreover, the DNTT transistor showed a good photoresponse to blue light with a wavelength of $450 \mathrm{~nm}$, with photoresponsivity $(R)$ of $50 \mathrm{~A} \mathrm{~W}^{-1}$ and a photocurrent/dark current ratio $(P)$ of 5 at a light intensity of $5 \mu \mathrm{W} \mathrm{cm} \mathrm{cm}^{-2}$.

\section{Introduction}

Organic field effect transistors (OFETs) have attracted tremendous attention due to their advantages such as low cost, light weight, and high flexibility. ${ }^{1}$ They cannot only be used to construct integrated circuits ${ }^{2}$ and backplanes, ${ }^{3}$ but also offer excellent possibilities for use as sensors. ${ }^{4}$ Phototransistors that can detect optical signals and convert optical variation into an electrical signal are one of the major applications of OFETs. The internal signal amplification function of the transistor device endows phototransistors with high photosensitivity and low noise. ${ }^{5}$ Great strides have been made over the last decades in the development of organic phototransistors (OPTs) with photoresponsivity $(R)$ up to $10^{4} \mathrm{~A} \mathrm{~W}^{-1}$ and photosensitivity, also called photocurrent/dark-current ratio, $(P)$ over $10^{5}$, exceeding those of Si-based phototransistors $\left(R \approx 300 \mathrm{~A} \mathrm{~W}^{-1}\right.$ and $\left.P \approx 10^{3}\right)$. However, there are still a lot of technical difficulties to be solved for commercial applications of OPTs. ${ }^{4 a, b}$ One of the key challenges comes from the high operating voltages of OFETs, often exceeding $20 \mathrm{~V}$, which leads to excessive energy consumption and poor integration capability to the terminal product. ${ }^{6}$ Therefore, successful implementation of the phototransistor technology in future generations of optical sensors not only requires the development of high performance device

${ }^{a}$ Key Lab of Special Display Technology, Ministry of Education, National Engineering Lab of Special Display Technology, State Key Lab of Advanced Display Technology, Academy of Opto-Electronic Technology, Hefei University of Technology, Hefei, 230009, People's Republic of China.E-mail: xhwang11@hfut.edu.cn; lzhqiu@hfut. edu.cn

${ }^{b}$ Key Laboratory of Advanced Functional Materials and Devices, School of Chemistry and Chemical Engineering, Hefei University of Technology, Anhui Province, People's Republic of China architectures but also needs the demonstration of low operating voltage organic phototransistors.

Generally, the operating voltage of an OFET can be decreased by increasing the capacitance density of the gated dielectric. According to the formula of capacitance, $C_{\mathrm{i}}=\varepsilon_{\mathrm{o}} \kappa / d$, a large $C_{\mathrm{i}}$ can be achieved either by increasing the dielectric constant $(\kappa)$ or by decreasing the thickness $(d)$ of dielectric films. ${ }^{7}$ Therefore, OFETs driven by a relatively low voltage can be fabricated by increasing the capacitance of the gate insulating film using selfassembled monolayers (SAMs) ${ }^{8}$ high- $\kappa$ inorganic insulating films, ${ }^{9}$ cross-linked organic insulating polymers, ${ }^{10}$ or ionic liquids. ${ }^{11}$ Among them, hybrid gate dielectrics composed of selfassembled monolayers ${ }^{8}$ or multilayers ${ }^{12}$ on ultrathin inorganic oxides have proven to be excellent candidates for low-voltage OTFTs. ${ }^{13}$ The oxide-SAM hybrid gate dielectrics with thickness of a few nanometers can provide high capacitances above 500 $\mathrm{nF} \mathrm{cm}^{-2}$ for operating voltages below $2 \mathrm{~V}$, while still maintaining the leakage current as low as $1 \times 10^{-8} \mathrm{~A} \mathrm{~cm}^{-2} .^{6,14} \mathrm{In}$ order to grow metal oxide films with nanometer control, electrochemical oxidation, also named as anodization, is a good, effective and solution based technique. The self-healing nature $^{15}$ of the anodic oxide allows fabricating high performance devices on industrial-scale plastic substrates with considerable surface roughness. Especially, aluminum oxide $\left(\mathrm{AlO}_{x}\right)$ prepared by anodization has attracted tremendous attention for its high dielectric constant, low leakage current, low cost and environmental friendly process. ${ }^{\mathbf{1 4}}$

It is reported the variation in dielectric thickness and roughness surface can severely reduce the mobility of OFET device with ultrathin gate dielectrics. ${ }^{16}$ A recent study ${ }^{17}$ revealed such degradation is mainly caused by the charge scattering at the rough interface. Therefore, a properly designed smooth and continuous interface is essential in achieving optimum OFET 
performance. In this study, a stripping procedure was reported to prepare a smooth aluminum gate electrode with a mean roughness less than $1 \mathrm{~nm}$. $\mathrm{AlO}_{x}-\mathrm{SAM}$ hybrid dielectrics were prepared using potentiostatic anodization and the following modification with $n$-octadecyl phosphonic acid. The field-effect characteristics as well as photoresponse of organic transistors with dinaphtho[2,3-b:2', $\left.3^{\prime}-f\right]$ thieno[3,2- $\left.b\right]$ thiophene (DNTT) as organic semiconductor ${ }^{18}$ were investigated as well.

\section{Results and discussion}

The stripping procedure for preparing aluminum electrode with ultra-smooth surface on flexible substrates was shown in Fig. 1. First, polystyrene (PS) was spin coated as a sacrificial layer on cleaned Si wafer at speed of $5000 \mathrm{rpm}$ for $40 \mathrm{~s} \mathrm{(Fig.} \mathrm{1b).} \mathrm{Then} \mathrm{an}$ aluminium layer was thermally evaporated onto the PS films (Fig. 1c). Flexible polyethylene terephthalate (PET) film coated with a UV-curing adhesive (UVAB) was covered on the aluminium surface. The adhesive layer was then solidified by using $365 \mathrm{~nm}$ UV-light for $10 \mathrm{~min}$ (Fig. 1d). After putting into cyclohexane for $1 \mathrm{~h}$ to remove the PS films, the aluminium layer buried in the UV-curing adhesive layer was separated from $\mathrm{Si}$ wafer (Fig. 1e). Finally, the ultra-smooth bottom surface of aluminum was fabricated and the composite films were flexible (Fig. 1f).

Atomic force microscope (AFM) and scanning electron microscopy (SEM) were applied to characterize the morphology of the aluminum surface. SEM images showed that the top surface of the as-deposited aluminum have a lot of particles (Fig. 2a), while the stripped bottom surface of the aluminum is quite smooth (Fig. 2b). AFM images revealed that the asdeposited aluminum films consist of small grains $(\sim 100-200$ $\mathrm{nm})$ separated by deep grain boundaries $(\sim 10 \mathrm{~nm})$ (Fig. $2 \mathrm{c})$. Apparently, the stripped bottom surface of aluminum is much smoother than the as deposited top surface (Fig. 2d). Root mean square roughness $\left(R_{\mathrm{q}}\right)$ was also calculated to characterize the smoothness of the surface. The $R_{\mathrm{q}}$ of the as-deposited top surface of the aluminum is $3.95 \mathrm{~nm}$ which is much higher than the $R_{\mathrm{q}}$ of $0.91 \mathrm{~nm}$ for the stripped bottom surface.

Potentiostatic anodization is adopted to achieve $\mathrm{AlO}_{x}$ with controlled thickness. ${ }^{19}$ Fig. 3a showed cross-sectional FETEM image of oxide aluminum anodized at $10 \mathrm{~V}$ for $600 \mathrm{~s}$. There is a clear boundary between aluminum layer and $\mathrm{AlO}_{x}$ layer. $\mathrm{A}$ (a)

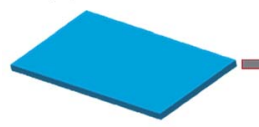

(d)

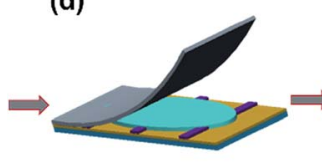

(e)

(c)

(b)

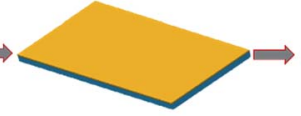

(e)

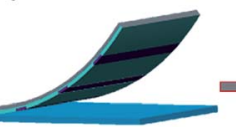

(a)

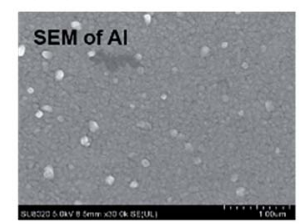

(c)

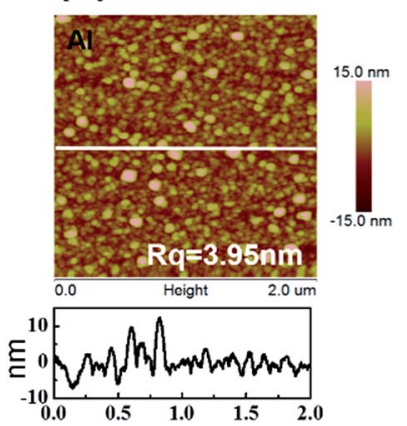

(b)

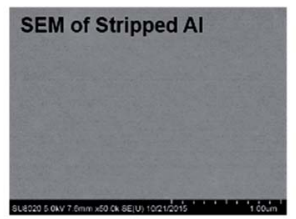

(d)

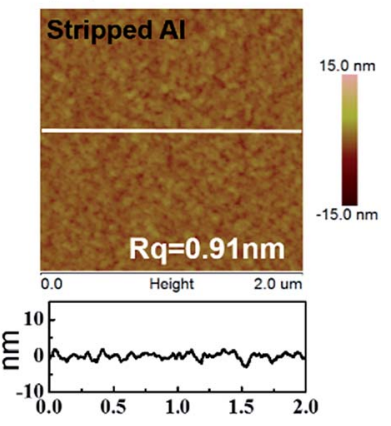

Fig. 2 (a) SEM image of as-deposited aluminum on glass, (b) SEM image of stripped aluminum on PET, (c) AFM image of as-deposited aluminum on glass, (d) AFM image of stripped aluminum on PET.

uniform $\mathrm{AlO}_{x}$ layer with thickness about $32 \mathrm{~nm}$ is observed. Energy-dispersive X-ray (EDX) was used to analyze element of each layers. Fig. $3 \mathrm{~b}$ and $\mathrm{c}$ demonstrated that $\mathrm{AlO}_{x}$ layer was successfully prepared. Fig. $3 \mathrm{~d}$ and e are the AFM images of the surface of the $\mathrm{AlO}_{x}$ layer prepared on as-deposited surface and stripped surface. The $R_{\mathrm{q}}$ of the $\mathrm{AlO}_{x}$ on the as-deposited surface is $5.20 \mathrm{~nm}$ and the $R_{\mathrm{q}}$ of the $\mathrm{AlO}_{x}$ on the stripped surface is $1.50 \mathrm{~nm}$. Compared to the surface of aluminum, the roughness, the height of the particle and the diameter of the granule on the anodized $\mathrm{AlO}_{x}$ increased slightly, which is similar to the results reported in ref. 14 and $16 a$.

The metal-insulator-metal (MIM) structure was used to assess the dielectric properties leakage current density ( $\left.J_{\text {leak }}\right)$ and capacitance density $\left(C_{\mathrm{i}}\right)$ characteristics ${ }^{20}$ For comparison,
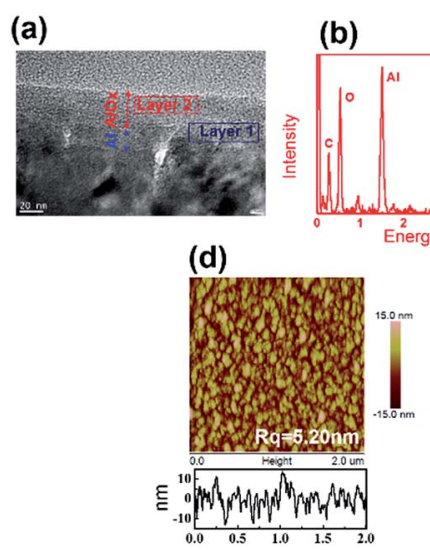

(b)

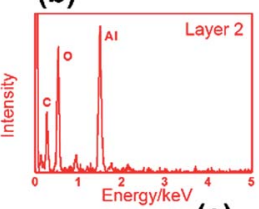

(e) (c)
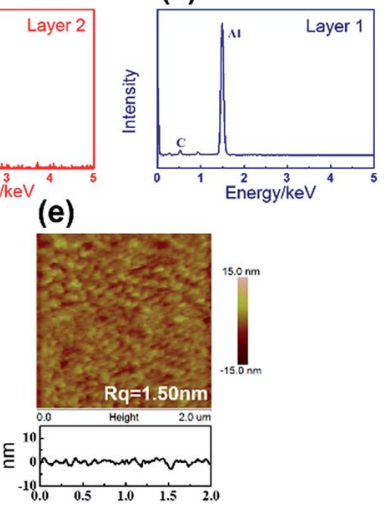

Fig. 3 (a) High-resolution cross-sectional FETEM image of the $\mathrm{AlO}_{x}$ on stripped Al prepared by potentiostatic anodization, (b and c) EDX analysis on the selective area in (a). (d) AFM image of the anodized $\mathrm{AlO}_{x}$ on as-deposited Al. (e) AFM image of the anodized $\mathrm{AlO}_{x}$ on stripped Al.
Fig. 1 Schematic description for the tripping procedure for fabricating flexible and ultra-smooth aluminium. 
the surfaces of the as-prepared aluminum and the stripped aluminum were oxidized by $\mathrm{O}_{3}$ plasma and potentiostatic anodization, respectively, and then were modified with selfassembled monolayer of $n$-octadecyl phosphonic acid. The specific conditions of the four dielectrics fabricated by different ways were listed in Table 1 . Current density vs. voltage and capacitance density $v s$. frequency were measured and showed in Fig. $4 \mathrm{a}$ and $\mathrm{b}$. It can be seen that the current density of both dielectrics oxidized by oxygen plasma (sample 1 and 2) increased rapidly as the increase of voltage. The $J_{\text {leak }}$ at $2 \mathrm{~V}$ was about $10^{-4} \mathrm{~A} \mathrm{~cm}^{-2}$. Although the $J_{\text {leak }}$ of plasma grown $\mathrm{AlO}_{x}$ in our work was much poorer than that reported by Klauk, ${ }^{21}$ it was comparable with the result reported by Acton $^{8 d}$ which indicated that tremendous optimizations were required for the application of the plasma grown $\mathrm{AlO}_{x}$ with thickness about $4.0 \mathrm{~nm}$ as a dielectric layer. Remarkably, anodized $\mathrm{AlO}_{x}$ on stripped aluminum (sample 4 ) reduced $J_{\text {leak }}$ by nearly three orders of magnitude to $10^{-7} \mathrm{~A} \mathrm{~cm}^{-2}$ at an applied voltage of $2 \mathrm{~V}$. In contrast, anodized $\mathrm{AlO}_{x}$ on as-deposited aluminum (sample 3) only reduced $J_{\text {leak }}$ by about two orders of magnitude to $10^{-6} \mathrm{~A}$ $\mathrm{cm}^{-2}$. The significant small $J_{\text {leak }}$ of sample 4 compared to sample 3 was likely from the combination of a more homogeneous $\mathrm{AlO}_{x}$ layer with a more closely packed SAM derived from the ultra-smooth stripped aluminum. The low $J_{\text {leak }}$ of $\mathrm{AlO}_{x}-\mathrm{SAM}$ hybrid dielectrics prepared on stripped aluminum via anodization make it as good gate dielectrics. The $C_{\mathrm{i}}$ characteristics between $100 \mathrm{~Hz}$ and $100 \mathrm{kHz}$ of four $\mathrm{AlO}_{x}-\mathrm{SAM}$ hybrid dielectrics are presented in Fig. $4 \mathrm{~b}$. The capacitance density of $\mathrm{AlO}_{x^{-}}$ SAM hybrid dielectrics prepared on stripped aluminum via anodization is $0.114 \mu \mathrm{F} \mathrm{cm} \mathrm{cm}^{-2}$. Assuming a permittivity of 2.5 and a thickness of $2.1 \mathrm{~nm}$ for the SAM as reported in literature $\mathrm{6}^{6,22}$ and a measured thickness of $32 \mathrm{~nm}$ for the aluminium oxide, the permittivity of $\mathrm{AlO}_{x}$ was calculated as $\varepsilon=4.6$ according to the formulation: $1 / C_{\text {total }}=1 / C_{\mathrm{SAM}}+1 / C_{\mathrm{AlO}_{x}}$, which agreed with the reported value of $\varepsilon$ for thin aluminum oxide films. ${ }^{7}$

The bottom-gate and top-contact configuration was used to fabricate four types of devices. Aluminum was used as gate electrode, $\mathrm{AlO}_{x}$ hybrid dielectrics grown on it were used as gate insulator. After thermal deposition of DNTT semiconductor layer, Au was deposited as source and drain electrode. The stripped aluminum on PET substrate shows very good flexibility (Fig. 5a). Fig. 5b-i showed the transfer and output curve of OTFTs based on different kinds of $\mathrm{AlO}_{x}$-SAM dielectric layers listed in Table 1. Because all four $\mathrm{AlO}_{x}$-SAM dielectrics have relative high capacitance density ranging from 1.01 to $0.114 \mu \mathrm{F}$ $\mathrm{cm}^{-2}$, their OTFTs can operate at a relative low voltage below $-5 \mathrm{~V}$. The $\mathrm{AlO}_{x}-\mathrm{SAM}$ prepared from anodization is much (a)

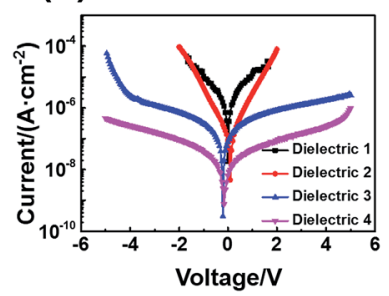

(b)

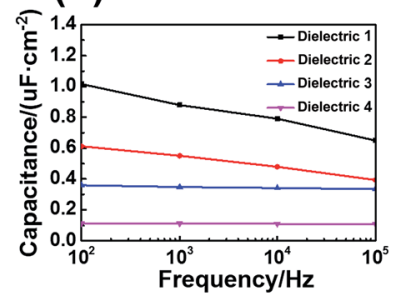

Fig. 4 (a) Current density as a function of voltage for four samples. (b) Capacitance density as a function of frequency for four samples.
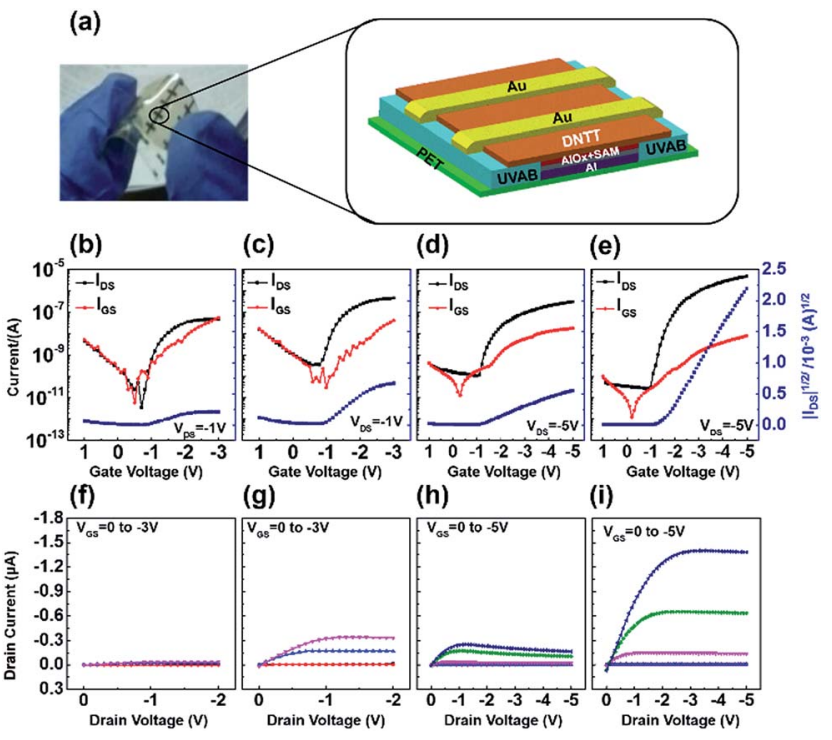

Fig. 5 (a) Photograph of the flexible OTFTs and schematic view of a top contact device using $\mathrm{Al}$ as the gate electrode and $n$-octadecyl phosphonic acid self-assembled monolayer modified $\mathrm{AlO}_{x}$ as the gate dielectric. (b-i) Typical output and transfer characteristics of OTFTs of the four types of dielectrics.

thicker than that prepared from $\mathrm{O}_{3}$ treatment; the OTFT devices based on dielectric 3 and 4 can withstand higher voltage than dielectric 1 and 2. Moreover, the gate leakage currents of anodized $\mathrm{AlO}_{x}$-SAM were one order of magnitude smaller than plasma grown $\mathrm{AlO}_{x}-\mathrm{SAM}$ from the same substrate. The mobility, threshold voltage $\left(V_{\text {th }}\right)$, on/off current ratio $\left(I_{\text {on/off }}\right)$, subthreshold swing (SS) were calculated and compared in Table 2. The OTFTs based on the anodized $\mathrm{AlO}_{x}-\mathrm{SAM}$ hybrid dielectrics prepared on stripped aluminum exhibited the highest mobility of $0.53 \mathrm{~cm}^{2} \mathrm{~V}^{-1} \mathrm{~s}^{-1}$ with a $V_{\text {th }}$ of $-1.51 \mathrm{~V}$, an $I_{\text {on/off }}$ of

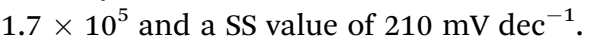

Table 1 Specific preparation conditions of the four different dielectrics

\begin{tabular}{llll}
\hline & Aluminum surface & Dielectric treatment & Surface modification \\
\hline Dielectric 1 & As-deposited & $\mathrm{O}_{3}$ plasma & $n$-Octadecyl phosphonic acid \\
Dielectric 2 & Stripped & $\mathrm{O}_{3}$ plasma & $n$-Octadecyl phosphonic acid \\
Dielectric 3 & As-deposited & Anodization & $n$-Octadecyl phosphonic acid \\
Dielectric 4 & Stripped & Anodization & $n$-Octadecyl phosphonic acid
\end{tabular}


Table 2 The performance of OTFTs with four different dielectric layers

\begin{tabular}{lllll}
\hline Dielectric & $\begin{array}{l}\text { Average mobility } \\
\left(\mathrm{cm}^{2} \mathrm{~V}^{-1} \mathrm{~s}^{-1}\right)\end{array}$ & $\begin{array}{l}\text { Max mobility } \\
\left(\mathrm{cm}^{2} \mathrm{~V}^{-1} \mathrm{~s}^{-1}\right)\end{array}$ & $V_{\text {th }}(\mathrm{V})$ & $I_{\text {on/off }}$ \\
\hline Dielectric 1 & $5.3 \times 10^{-3}$ & $7.4 \times 10^{-3}$ & -0.85 & $1.2 \times 10^{4}$ \\
Dielectric 2 & $3.9 \times 10^{-2}$ & $5.0 \times 10^{-2}$ & -0.95 & -0.13 \\
Dielectric 3 & $1.1 \times 10^{-2}$ & $2.3 \times 10^{-2}$ & -1.00 & -0.22 \\
Dielectric 4 & $3.5 \times 10^{-1}$ & $5.3 \times 10^{-1}$ & -1.51 & $1.2 \times 10^{4}$ \\
\end{tabular}

DNTT as the semiconductor has photoresponsivity to the blue light with the wavelength of $450 \mathrm{~nm}$. The optoelectronic properties of the DNTT phototransistors were measured under illumination of a light-emitting diode (LED) lamp (450 nm) in air. The incidence light intensity was measured with a calibrate silicon photodiode. The illumination area on the device was defined as the area of the active channel, i.e. $8.33 \times 10^{-3} \mathrm{~cm}^{2}$. Fig. 6a presents the molecular structure of DNTT. The UV-vis absorption spectra of DNTT in chloroform solution is shown in Fig. 6b. The DNTT solution exhibited clearly absorption band at $450 \mathrm{~nm}$. It indicated that DNTT has photoresponsivity of the blue light with the wavelength of $450 \mathrm{~nm}$. The field-effect characteristics of the devices under light illumination with different intensities were characterized. As shown in Fig. 6a and b, when these devices were exposed to the blue light, the drain current clearly increased as the intensities of the light illumination became stronger. A weak light intensity of $5 \mu \mathrm{W} \mathrm{cm}$ (a)

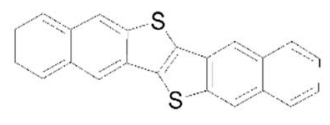

(c)

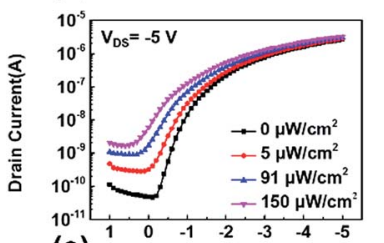

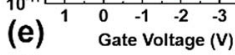

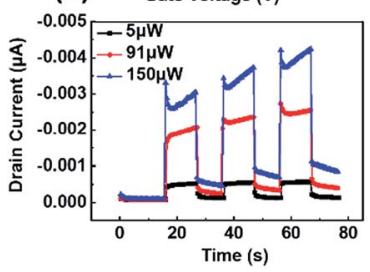

(b)

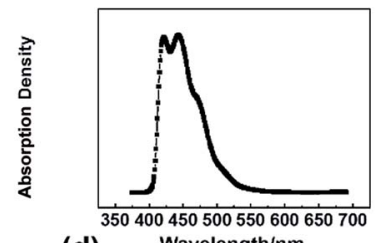

(d)
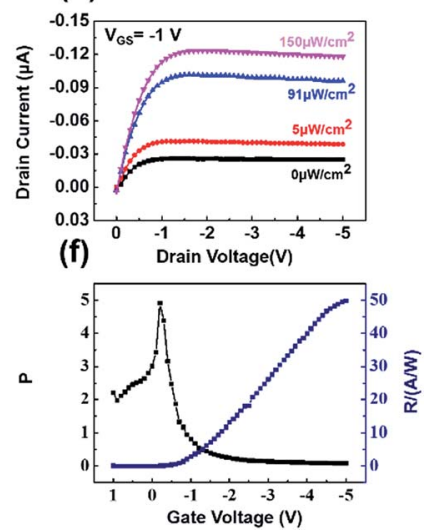

Fig. 6 (a) Chemical structure of DNTT. (b) UV-vis absorption spectra of DNTT solution. (c) Photodetectors in the dark and different light intensities of $5 \mu \mathrm{W} \mathrm{cm}-2,91 \mu \mathrm{W} \mathrm{cm}-2,150 \mu \mathrm{W} \mathrm{cm} \mathrm{cm}^{-2}$. (d) Output characteristics of DNTT photodetectors measured at different light intensities. (e) The photoresponse of the DNTT with the light switched "on" and "off" under given wavelength of $450 \mathrm{~nm}$. (f) Photoresponsivity $(R)$ and photocurrent/dark current ratio $(P)$ of photodetectors based on DNTT. can be detected by our transistors. The photoswitching properties of DNTT phototransistors were also investigated and showed in Fig. 6c. The photocurrent sharply increased at an "ON" state under light irradiation, while it decreased quickly to an "OFF" state as the light turned off. ${ }^{23}$ The on/off current ratio of the devices was 30 when the light intensity was $150 \mu \mathrm{W} \mathrm{cm}{ }^{-2}$. Photoresponsivity $(R)$ and photocurrent/dark-current ratio $(P)$ are crucial parameters assessing the performance of phototransistors, which are defined by the following equations:

$$
\begin{gathered}
R=\left(I_{\text {ill }}-I_{\text {dark }}\right) / P_{\text {ill }} \\
P=\left(I_{\text {ill }}-I_{\text {dark }}\right) / I_{\text {dark }}
\end{gathered}
$$

where $I_{\text {ill }}$ is the drain current under illumination, $I_{\text {dark }}$ is the drain current in darkness, $P_{\text {ill }}$ is the incident illumination power on the channel. The $R$ and $P$ values of the phototransistor based on DNTT were shown in Fig. $6 \mathrm{~d}$. The highest $R$ and $P$ were $50 \mathrm{~A}$ $\mathrm{W}^{-1}$ and 5 with the light intensity of $5 \mu \mathrm{W} \mathrm{cm}^{-2}$. Such a high photosensitivity under low illumination power $\left(=5 \mu \mathrm{W} \mathrm{cm}{ }^{-2}\right)$ indicates that the flexible low-voltage DNTT OTFT can be an efficient photosensor.

\section{Conclusions}

In conclusion, a stripping method has been developed to achieve smooth aluminum gate electrode. The roughness of stripped aluminum electrode is decreased dramatically to $0.9 \mathrm{~nm}$ compared with the value of $3.5 \mathrm{~nm}$ for as-deposited aluminum. After the aluminum gate electrode was potentiostatic anodized, the roughness of the alumina increased slightly. The bottom surface of the aluminum oxidized by potentiostatic anodization and then modified by $n$-ocadecyl phosphonic acid is an appropriate insulating layer with the leakage current density of about $10^{-7} \mathrm{~A} \mathrm{~cm}^{-2}$ at the voltage of $-2 \mathrm{~V}$, and the capacitance density of $0.114 \mu \mathrm{F} \mathrm{cm}{ }^{-2}$. The DNTT OTFTs with the stripping $\mathrm{AlO}_{x}$ anodized by potentiostatic anodization exhibit good charge transfer characteristics with a mobility of $0.53 \mathrm{~cm}^{2} \mathrm{~V}^{-1} \mathrm{~s}^{-1}$. OTFTs based on DNTT semiconductor shown photoresponsivity to the $450 \mathrm{~nm}$ blue light and can detect weak light intensity as low as $5 \mu \mathrm{W} \mathrm{cm} \mathrm{cm}^{-2}$.

\section{Experimental}

\section{The procedure used for fabrication of the aluminum electrode}

Silicon wafers and $2.5 \mathrm{~mm}$ thick PET films were cleaned in acetone, ethanol, de-ionized water, then dried on hot plate at $120^{\circ} \mathrm{C}$ for $15 \mathrm{~min}$. After treated with oxygen-plasma for $15 \mathrm{~min}$, 
$10 \mathrm{mg} \mathrm{mL}{ }^{-1} \mathrm{PS} / \mathrm{chloroform}$ solution was spin coated on the cleaned Si wafers at $5000 \mathrm{rpm}$. Aluminum film was evaporated on PS through a shadow mask. Then, UVAB coated PET films were covered on aluminum film, and solidified by irradiating $365 \mathrm{~nm}$ UV light for $5 \mathrm{~min}$. The composite films were immersed in cyclohexane to dissolve PS. The buried aluminum on the surface of the UVAB adhered to PET films was peeled off from the Si wafers.

\section{Preparation of aluminum oxide and phosphonic acid self- assembled monolayers}

The high- $\kappa$ aluminum oxide gate dielectric layer was formed by potentiostatic anodization under ambient conditions (CHI660D electrochemical workstation, Shanghai Chen Hua Instrument Co., Ltd). A $0.0075 \mathrm{M}$ citric acid monohydrate $\left(\mathrm{C}_{6} \mathrm{H}_{8} \mathrm{O}_{2} \cdot \mathrm{H}_{2} \mathrm{O}\right)$ electrolyte was prepared with ultrapure water $(18 \mathrm{M} \Omega \mathrm{cm})$. The contacted gates were immersed in the electrolyte to form the working electrode (anode), and platinum wire served as counter electrode, $\mathrm{Ag} / \mathrm{AgCl}$ served as reference electrode. The aluminum film was then anodized with a constant voltage of $10 \mathrm{~V}$ for $10 \mathrm{~min}$ in a $0.0075 \mathrm{M}$ citric acid monohydrate solution at $25^{\circ} \mathrm{C}$. The high- $\kappa$ aluminum oxide gate dielectric layer was also can formed by oxygen-plasma treatment. The oxygen-plasma process was carried out for $30 \mathrm{~min}$ at $25{ }^{\circ} \mathrm{C}$ by UV-ozone treatment.

Phosphonic acid self-assembled monolayers were prepared into solutions of $3 \mathrm{mM} n$-octadecyl phosphonic acid in isopropanol at room-temperature. The substrates were immersed in solution at room-temperature for $30 \mathrm{~min}$, then rinsed with tetrahydrofuran followed by ethanol. Finally, these substrates were put on the hot plate at $100{ }^{\circ} \mathrm{C}$ to remove residual solvent.

\section{Device fabrication}

DNTT was then deposited onto substrates by thermal evaporation. Source and drain electrodes $(W=85 \mu \mathrm{m}, L=980 \mu \mathrm{m})$ were defined on top of the DNTT by evaporating a $50 \mathrm{~nm}$-thick gold film through a shadow mask.

\section{Characterization}

The morphologies of the aluminum electrode and were characterized by scanning electron microscopy (Hitachi SU8020) and atomic force microscopy (AFM) in tapping mode (Digital Instruments Multimode). The electrical characterization of the devices was measured by a Keithley 4200-SCS semiconductor parametric.

\section{Acknowledgements}

We thank the National Natural Science Foundation of China (Grant No. 51573036) and the Program for New Century Excellent Talents in University (Grant No. NCET-12-0839).

\section{References}

1 (a) J. Sun, B. Zhang and H. E. Katz, Adv. Funct. Mater., 2011, 21, 29; (b) S. Vasimalla, N. V. V. Subbarao and P. K. Iyer, J.
Mater. Chem. C, 2016, 4, 7102; (c) Y. Xu, C. Liu, D. Khim and Y. Y. Noh, Phys. Chem. Chem. Phys., 2015, 17, 26553; (d) J. Lu, K.-S. Moon and C. P. Wong, in 12th International Symposium on Advanced Packaging Materials: Processes, Properties, and Interfaces, 2007, p. 187; (e) H. Ma, H. L. Yip, F. Huang and A. K. Y. Jen, Adv. Funct. Mater., 2010, 20, 1371; (f) T. H. Huang, K. C. Liu, Z. Pei, W. K. Lin and S. T. Chang, Org. Electron., 2011, 12, 1527.

2 (a) J. Reeder, M. Kaltenbrunner, T. Ware, D. Arreaga-Salas, A. Avendano-Bolivar, T. Yokota, Y. Inoue, M. Sekino, W. Voit, T. Sekitani and T. Someya, Adv. Mater., 2014, 26, 4967; (b) U. Zschieschang, F. Ante, T. Yamamoto, K. Takimiya, H. Kuwabara, M. Ikeda, T. Sekitani, T. Someya, K. Kern and H. Klauk, Adv. Mater., 2010, 22, 982; (c) U. Zschieschang, F. Ante, D. Kaelblein, T. Yamamoto, K. Takimiya, H. Kuwabara, M. Ikeda, T. Sekitani, T. Someya, J. Blochwitz-Nimoth and H. Klauk, Org. Electron., 2011, 12, 1370.

3 (a) P. F. Yu, W. Tang, L. R. Feng, J. Q. Zhao, Y. T. Li, Y. J. Liu and X. J. Guo, J. Disp. Technol., 2016, 12, 690; (b) T. Yokota, T. Sekitani, T. Tokuhara, N. Take, U. Zschieschang, H. Klauk, K. Takimiya, T. C. Huang, M. Takamiya, T. Sakurai and T. Someya, IEEE Trans. Electron Devices, 2012, 59, 3434.

4 (a) J. Milvich, T. Zaki, M. Aghamohammadi, R. Rödel, U. Kraft, H. Klauk and J. N. Burghartz, Org. Electron., 2015, 20, 63; (b) L. Zhang, T. Wu, Y. L. Guo, Y. Zhao, X. N. Sun, Y. G. Wen, G. Yu and Y. Q. Liu, Sci. Rep., 2013, 3, 1080; (c) X. Liu, Y. Guo, Y. Ma, H. Chen, Z. Mao, H. Wang, G. Yu and Y. Liu, Adv. Mater., 2014, 26, 3631.

5 M. Zhu, S. Lv, Q. Wang, G. Zhang, H. B. Lu and L. Qiu, Nanoscale, 2016, 8, 7738.

6 O. Acton, G. G. Ting, P. J. Shamberger, F. S. Ohuchi, H. Ma and A. K. Y. Jen, ACS Appl. Mater. Interfaces, 2010, 2, 511.

7 L. A. Majewski, R. Schroeder, M. Grell, P. A. Glarvey and M. L. Turner, J. Appl. Phys., 2004, 96, 5781.

8 (a) F. Colleaux, J. M. Ball, P. H. Wobkenberg, P. J. Hotchkiss, S. R. Marder and T. D. Anthopoulos, Phys. Chem. Chem. Phys., 2011, 13, 14387; (b) N. Björklund, F. S. Pettersson, D. Tobjörk and R. Österbacka, Synth. Met., 2011, 161, 743; (c) H. Ma, O. Acton, D. O. Hutchins, N. Cernetic and A. K. Y. Jen, Phys. Chem. Chem. Phys., 2012, 14, 14110; (d) O. Acton, D. Hutchins, L. Arnadottir, T. Weidner, N. Cernetic, G. G. Ting, T. W. Kim, D. G. Castner, H. Ma and A. K. Y. Jen, Adv. Mater., 2011, 23, 1899; (e) J. Collet, O. Tharaud, A. Chapoton and D. Vuillaume, Appl. Phys. Lett., 2000, 76, 1941.

9 (a) Q. Zhang, G. Xia, W. Xia, J. Zhou and S. Wang, Synth. Met., 2015, 210, 282; (b) Y. M. Park, A. Desai, A. Salleo and L. Jimison, Chem. Mater., 2013, 25, 2571; (c) L. A. Majewski, R. Schroeder and M. Grell, Adv. Funct. Mater., 2005, 15, 1017; (d) J. D. Oh, J. W. Kim, D. K. Kim and J. H. Choi, Org. Electron., 2016, 30, 131.

10 (a) M. H. Yoon, H. Yan, A. Facchetti and T. J. Marks, J. Am. Chem. Soc., 2005, 127, 10388; (b) M. E. Roberts, N. Queraltó, S. C. B. Mannsfeld, B. N. Reinecke, W. Knoll and Z. Bao, Chem. Mater., 2009, 21, 2292; (c) W. Xu and 
S. W. Rhee, J. Mater. Chem., 2009, 19, 5250; (d) Y. G. Ha, S. Jeong, J. S. Wu, M. G. Kim, V. P. Dravid, A. Facchetti and T. J. Marks, J. Am. Chem. Soc., 2010, 132, 17426; (e) C. Wang, W. Y. Lee, R. Nakajima, J. Mei, D. H. Kim and Z. Bao, Chem. Mater., 2013, 25, 4806; $(f)$ E. Reis Simas, E. S. H. Kang, A. Gassmann, E. Katholing and H. V. Seggern, J. Mater. Chem. C, 2015, 3, 9217; (g) S. Faraji, E. Danesh, D. J. Tate, M. L. Turner and L. A. Majewski, J. Phys. D: Appl. Phys., 2016, 49, 185102.

11 (a) T. Uemura, M. Yamagishi, S. Ono and J. Takeya, Appl. Phys. Lett., 2009, 95, 103301; (b) S. Ono, K. Miwa, S. Seki and J. Takeya, Org. Electron., 2009, 10, 1579; (c) T. Uemura, R. Hirahara, Y. Tominari, S. Ono, S. Seki and J. Takeya, Appl. Phys. Lett., 2008, 93, 263305; (d) S. Ono, S. Seki, R. Hirahara, Y. Tominari and J. Takeya, Appl. Phys. Lett., 2008, 92, 103313; (e) T. Uemura, M. Yamagishi, S. Ono and J. Takeya, Jpn. J. Appl. Phys., 2010, 49, 01AB13.

12 (a) B. H. Lee, M. K. Ryu, S. Y. Choi, K. H. Lee, S. Im and M. M. Sung, J. Am. Chem. Soc., 2007, 129, 16034; (b) K. S. Han, Y. Park, G. Han, B. H. Lee, K. H. Lee, D. H. Son, S. Im and M. M. Sung, J. Mater. Chem., 2012, 22, 19007; (c) K. Everaerts, J. D. Emery, D. Jariwala, H. J. Karmel, V. K. Sangwan, P. L. Prabhumirashi, M. L. Geier, J. J. McMorrow, M. J. Bedzyk, A. Facchetti, M. C. Hersam and T. J. Marks, J. Am. Chem. Soc., 2013, 135, 8926; (d) Y. G. Ha, K. Everaerts, M. C. Hersam and T. J. Marks, Acc. Chem. Res., 2014, 47, 1019; (e) V. K. Sangwan, D. Jariwala, K. Everaerts, J. J. McMorrow, J. T. He, M. Grayson, L. J. Lauhon, T. J. Marks and M. C. Hersam, Appl. Phys. Lett., 2014, 104, 083503.

13 S. A. DiBenedetto, A. Facchetti, M. A. Ratner and T. J. Marks, Adv. Mater., 2009, 21, 1407.
14 A. Dey, A. Singh, A. Kalita, D. Das and P. K. Iyer, in IndiaJapan Expert Group Meeting on Biomolecular Electronics \& Organic Nanotechnology for Environment Preservation, ed. A. Fujii, B. D. Malhotra, H. Kajii and S. Kumar, 2016, vol. 704.

15 M. Kaltenbrunner, T. Sekitani, J. Reeder, T. Yokota, K. Kuribara, T. Tokuhara, M. Drack, R. Schwödiauer, I. Graz, S. Bauer-Gogonea, S. Bauer and T. Someya, Nature, 2013, 499, 458.

16 (a) L. A. Majewski, R. Schroeder, M. Voigt and A. M. Grell, J. Phys. D: Appl. Phys., 2005, 870, 3367; (b) C. Yang, K. Shin, S. Y. Yang, H. Jeon, D. Choi, D. S. Chung and C. E. Park, Appl. Phys. Lett., 2006, 89, 153508.

17 S. Saito, K. Torii, Y. Shimamoto, S. Tsujikawa, H. Hamamura, O. Tonomura, T. Mine, D. Hisamoto, T. Onai, J. Yugami, M. Hiratani and S. Kimura, Appl. Phys. Lett., 2004, 84, 1395.

18 (a) T. Yamamoto and K. Takimiya, J. Am. Chem. Soc., 2007, 129, 2224; (b) T. Yamamoto and K. Takimiya, $J$. Photopolym. Sci. Technol., 2007, 20, 57.

19 N. V. V. Subbarao, M. Gedda, S. Vasimalla, P. K. Iyer and D. K. Goswami, Phys. Status Solidi A, 2014, 211, 2403.

20 (a) A. I. Mardare, M. Kaltenbrunner, N. S. Sariciftci, S. Bauer and A. W. Hassel, Phys. Status Solidi A, 2012, 209, 813; (b) K. Kang Dae and S. Chung Kun, Appl. Phys. Lett., 2006, 88, 233508.

21 H. Klauk, U. Zschieschang, J. Pflaum and M. Halik, Nature, 2007, 445, 745.

22 M. S. Go, J. M. Song, C. Kim, J. Lee, J. Kim and M. J. Lee, Electron. Mater. Lett., 2015, 11, 252.

23 Q. H. Wang, M. Zhu, D. Wu, G. B. Zhang, X. H. Wang, H. B. Lu, X. H. Wang and L. Z. Qiu, J. Mater. Chem. C, 2015, 3, 10734. 